OPEN ACCESS

Edited by:

Ahmad Alkhatib,

University of Taipei, Taiwan

Reviewed by:

Huabin Luo,

East Carolina University, United States

Eugenia M. Bastos, Independent Researcher,

Sommerville, United States

*Correspondence:

Shaoliang Tang

tangshaoliang@126.com

Specialty section:

This article was submitted to Life-Course Epidemiology and Social

Inequalities,

a section of the journal

Frontiers in Public Health

Received: 09 July 2020 Accepted: 28 September 2020 Published: 28 October 2020

Citation:

Tang S, Zhang R, Si Y, Cheng Y and Gong $Y$ (2020) Measurement of the Equality of the Drug Welfare Induction Level of Chinese Patients With Chronic Diseases in Gansu, Sichuan, Hebei, and Zhejiang Based on the Bivariate Theil-T Index Method. Front. Public Health 8:581533. doi: 10.3389/fpubh.2020.581533

\section{Measurement of the Equality of the Drug Welfare Induction Level of Chinese Patients With Chronic Diseases in Gansu, Sichuan, Hebei, and Zhejiang Based on the Bivariate Theil-T Index Method}

\author{
Shaoliang Tang*, Ruxia Zhang, Yinghang Si, Yan Cheng and Ying Gong \\ School of Health Economics and Management, Nanjing University of Chinese Medicine, Nanjing, China
}

Objectives: This study aimed to measure the induction level of drug welfare in Chinese patients with chronic diseases using a bivariate Theil index.

Design: The bivariate Theil-T index was used to hierarchically decompose the relevant survey data, and the contribution rate of the intragroup gap and the intergroup gap to the total gap was investigated to better understand the current drug welfare induction level of Chinese patients with chronic diseases.

Setting: The study was based in Gansu, Sichuan, Hebei, and Zhejiang provinces in China.

Participants: Survey data was from patients with chronic diseases in 20 hospitals in four provinces.

Primary and secondary outcome measures: Data was collected through a questionnaire designed by the research team after expert consultation. Using the variables represented by the index system to decompose the Theil index from the two dimensions of the region and urban and rural areas. SPSS 22.0 was used for reliability and validity analysis and Theil index calculation.

Results: The overall level of drug welfare induction in Chinese patients with chronic diseases had a high degree of equalization. The overall Theil index was 0.0003 , but there were still some differences among groups.

Conclusions: To improve the drug welfare equalization induction level of patients with chronic diseases in China, the government should start from western rural areas, and policy should target the provinces that were in a disadvantaged position within the region to promote the equalization of drug welfare induction level for patients with chronic diseases in China.

Keywords: patients with chronic diseases, drug welfare induction, bivariate Theil-T index, measurement of equalization, health equality 


\section{INTRODUCTION}

With the change of the human disease spectrum, chronic diseases currently account for the majority of global morbidity, and mortality $(1,2)$. It is expected that by 2020 , chronic non-communicable diseases (chronic diseases) will become the leading cause of death and disability in humans $(3,4)$ and the most crucial disease burden in China. Chronic diseases have brought many challenges and burdens to patients and the health system. Whether the drug needed for treatment is obtained and affordable is the most significant way to effectively control the incidence and mortality of chronic diseases.

Chronic diseases, also known as non-communicable diseases (NCDS), are ongoing and often incurable diseases or conditions that require ongoing medical care and affect a person's daily life $(5,6)$. It reported that $80-92 \%$ of older adults have at least one chronic illness and $50-77 \%$ have two or more (7). Cardiovascular disease, arthritis, and diabetes are common chronic diseases. Some studies indicate that heart disease and cancer together account for nearly $46 \%$ of all deaths:(8). Older people with arthritis found that they have trouble with their normal activities $(9,10)$. Diabetes is the leading cause of kidney failure, lowerlimb amputation not due to injury, and new cases of blindness among adults (11). Moreover, it has also been reported that $\sim 63 \%$ of all deaths in the world are attributed to NCDs, and this causes great socioeconomic harm to all countries, particularly developing countries (12).

The disease characteristics of chronic diseases determine that patients with chronic diseases need to take drugs for a long time, and the cost of medicines accounts for the vast majority of medical expenses. Due to the fragility of their social status, chronically ill patients are often at the most disadvantaged position for access to basic health services, especially medicines, which will directly affect their health and drug welfare effects. The expenditure of chronic disease drugs brings many challenges and burdens to the patients themselves and the health system (13). Whether the drugs needed for treatment can be obtained and can afford them is the most important to effectively control the incidence and mortality of chronic diseases. In addition, the equalization of basic public goods is an important goal for the future development of Chinese society. As a special commodity, medicines belong to the category of quasi-public products, and ensuring the fairness of medicines is an important basis for achieving the health of the whole people.

The Chinese government is aware of the seriousness of this problem. Since the new medical reform in 2009 , the state has successively introduced and implemented relevant drug policies, such as the basic drug system, the zero-rate policy for essential drugs, and the centralized procurement of drugs in public hospitals. It is of vital importance to improve the level of drug welfare in Chinese patients. One of the landmark initiatives is

\footnotetext{
Abbreviations: BMI, Body mass index; T, Total gap; $\mathrm{T}_{\mathrm{Br}}$, Gap between regions; $\mathrm{T}_{\mathrm{Bc}}$, Gap between cities; $\mathrm{T}_{\mathrm{Wr}}$, Gap within the region; $\mathrm{T}_{\mathrm{Wc}}$, Gap within urban and rural areas; $\mathrm{T}_{\mathrm{WrBc}}$, Gap within the region between urban and rural areas; $\mathrm{T}_{\mathrm{Wrc}}$, Gap within the region within urban and rural areas; $\mathrm{T}_{\mathrm{WcBr}}$, Gap within urban and rural areas between regions; $\mathrm{T}_{\mathrm{Wcr}}$, Gap within urban and rural areas within the region.
}

the issuance of a national essential medicines system with the specific goal of improving the supply of medicines and ensuring equitable access to essential medicines. Since the implementation, the overall burden of medicine for patients with chronic diseases has improved (14), but it still faces a severe situation. The survey showed that patients with type 2 diabetes (T2DM) who used oral antidiabetic drugs (OADs) in China had a heavy financial burden, with direct treatment costs and opportunity costs accounting for $56 \%$ of the patient's disposable income (15).

The main contributions of this research include three aspects: First, due to the widespread urban-rural differences and regional differences in China, and the different socioeconomic systems in different regions, we have carried out the level of drug welfare sensing for chronically ill patients through the hierarchical decomposition of the bivariate Theil index. Dimensional research. Secondly, we make full use of the survey data to reflect the actual situation more intuitively, and try to study the equalization of the drug welfare level from the perspective of Chinese chronic disease patients. Third, we seek to provide empirical support to policy makers to develop more effective drug policies and establish more effective public health management systems.

The rest of this article is organized as follows. The second part describes the samples and research methods. The third part analyzes the decomposition results of the bivariate Theil index. The fourth part discusses the empirical results. The fifth section summarizes the main conclusions.

\section{BACKGROUNDS IN DRUG WELFARE}

Domestic and foreign research on "drug welfare" generally refers to "Pharmacy Benefit Management" (PBM), which is a management coordination organization between insurance institutions, pharmaceutical companies, hospitals, and pharmacy. PBMs have the potential to secure lower drug prices and to improve rational prescribing (16). PBMs decides on the use of medicines in formulas and negotiates with pharmaceutical manufacturers and pharmacies on behalf of insurance companies. Through these activities, PBMs provides value by curbing drug spending (17).

Grabowski and Mullins analyzed the cost-effectiveness of drug welfare management in the United States, and proposed that $\mathrm{PBM}$ as a drug welfare management agency, through the control of hospital medical expenses and doctor behavior, control of medical insurance costs and the main profit of the pharmaceutical supply chain, the most important purpose was to improve patient utility (18). Tara L. Jenkins conducted a retrospective administrative analysis using the Oklahoma Health Care Pharmacy and Medical Claims Database, and the results showed although total health care expenditures increased after a monthly pharmacy benefit in a Medicaid population was expanded, a subpopulation of recipients identified as high pharmacy users before the expansion did not have a statistically significant increase in medical expenditures, and their pharmacy welfare status had not been significantly improved (19). Sean et al. explored the reasons why the private sector in Canada was unable 
to implement prescription drug cost control measures through semi-structured telephone interviews with relevant experts, and suggested that employees and employers needed to be educated to have more collaboration and data sharing between each other. It also required external government intervention to help transform the established norms of private drug program design with a view to improving employee private drug benefits (20). Lohrberg et al. analyzed the definition and role of QoL in German drug welfare assessment, and the use of QoL as a drug welfare standard emphasized the importance of defining QoL definitions and methodological regulations (21).

By combing the literature, it can be found that the research on drug welfare in the academic community mostly starts from the single dimension of the fairness of health resources, and lacks multi-dimensional exploration. We reviewed the relevant literature on the evaluation of drug welfare effects. Based on relevant theories and methods, combined with the characteristics of prevention and treatment of chronic diseases, and the uniqueness of patients with chronic diseases, from the perspective of multi-dimensional research, we studied the drug welfare induction level of chronic disease patients from four aspects: drug accessibility sensing level, drug price sensing level, drug fairness sensing level, and drug health sensing level.

\section{METHODS}

\section{Measuring Instruments}

The National Natural Science Foundation project hosted by the author, "Optimization of Health and Precision Poverty Alleviation Policy Based on the Improvement of the Drug Welfare Effect of Poverty Chronic Patients," has made a detailed study on the construction of the evaluation index system for the drug welfare level of patients with chronic diseases in China [Min (22) "Study on the Evaluation and Promotion Strategy of the Drug Welfare Effect of Patients with Chronic Diseases in 10 Provinces Based on the Topsis Method;" Yini (2018) (23) "Study on the Drug Welfare Effect of Patients with Chronic Diseases Based on the Two-Step Clustering Method"]. So according to the four aspects of patients' drug welfare induction level mentioned before, this study established an evaluation index system for drug welfare effects of chronic diseases patients (Table 1). The weight of each index was obtained by Delphi expert consultation method. The evaluation index system is shown in Table $\mathbf{1}$ and will not be discussed in this paper.

\section{Design of Questionnaire}

According to Table 1, the questionnaire on the drug welfare effect of patients with chronic diseases was compiled, which consisting of five parts: (1) Personal situation questionnaire (2) Drug accessibility questionnaire (3) Drug price effect questionnaire (4) Drug Fair Effect Questionnaire (5) European five-dimensional health scale. Except for personal situation, the other four parts were based on the chronic disease patients in Table 1.

- Part 1 included the basic sociodemographic information of hukou nature, gender, ethnicity, age, marital status, education level, occupation, average monthly income (yuan), type of medical insurance, employment status, current main source of income, health file, health checkup, types of chronic disease.

- Part 2 has six questions for knowing about the situation of drug accessibility induction level equalization.

- Part 3 has six questions for knowing about the situation of drug price effect induction level equalization.

- Part 4 has four questions for knowing about the situation of drug fair effect induction level equalization.

- Part 5 has five questions for knowing about the situation of drug health effect induction level equalization.

There are positive indicators and inverse indicators in the questionnaire. For the positive indicators, the larger the score is, the better the indicators. For the inverse indicators, the smaller the score is, the better the indicators. For the inverse indicators, the method of taking the reciprocal of the original indicator is adjusted. There are two reverse indicators in this article, namely, "I5: The cheap drugs needed are not accessible and I6: The expensive drugs needed are not affordable." This article has made relevant adjustments before using the data, and the rest of the indicators are all positive indicators. The questionnaire is detailed in Appendix 1.

\section{Participants and Sampling}

Our research was conducted in both eastern and western region in China, provinces with higher and lower per-capita gross domestic product were sampled. In 2018, Zhejiang province was ranked the fifth in terms of per capita GDP among the 31 provinces or municipalities in the mainland in China, with a GDP per capita of 99,000 yuan. Hebei province was the 20 th $(48,000$ yuan). Among the eastern regions, we selected Zhejiang province and Hebei province as the sample area with relatively high and low economic level among the eastern regions, which could better represent the areas in eastern China. At the same time, in the western region, Sichuan province, and Gansu province were ranked the 18 th (49,000 yuan) and 28 th (31,000 yuan) on per capita GDP, which could better represent the areas in western China.

Thus, four provinces were selected, two from each of these two regions. In total, 20 hospitals were sampled in our study. Each province was sampled according to their geographical distribution, and five hospitals were then randomly selected from each province. In each hospital, trained data collectors went to check patients' messages. After each interview, which lasted $\sim 15 \mathrm{~min}$, the participant received a small gift of thanks. Approximately 50 patients per hospital were selected for this study. Through questionnaire survey, relevant data of patients with chronic diseases were obtained, and informed verbal consent was obtained from the respondents; according to the scope of the items covered by the questionnaire, a face-toface questionnaire survey was conducted with individuals who were in the hospitals. Finally, Members of 1,000 patients were interviewed and the response rate was $99.2 \%$.

A total of 992 patients reported their messages about drug welfare induction level, of which 29 were excluded because they were not having chronic diseases. The total number of residents included in the analysis was 963 . We used the simple random 
TABLE 1 | Weighting evaluation system for equalization of drug welfare induction in patients with chronic diseases.

\begin{tabular}{|c|c|c|c|}
\hline Target layer & Index level one & Index level two & Weights \\
\hline \multirow[t]{18}{*}{$\begin{array}{l}\text { X: Drug welfare effect induction level } \\
\text { equalization }\end{array}$} & $\begin{array}{l}\text { A1: Drug accessibility effect induction level } \\
\text { equalization }\end{array}$ & $\begin{array}{l}\text { I1: The number of medical service institutions } \\
\text { that can be reached within } 15 \text { min }\end{array}$ & 0.1064 \\
\hline & & $\begin{array}{l}\text { 12: The needed drug can be purchased in } \\
\text { public medical heath institutions }\end{array}$ & 0.1127 \\
\hline & & $\begin{array}{l}\text { I3: The needed drug can be purchased in retail } \\
\text { pharmacies }\end{array}$ & 0.1032 \\
\hline & & $\begin{array}{l}\text { 14: The needed drug can be purchased in } \\
\text { online pharmacies }\end{array}$ & 0.0694 \\
\hline & & 15: The cheap needed drug is not accessible & 0.3105 \\
\hline & & 16: The expensive needed drug is not affordable & 0.2978 \\
\hline & $\begin{array}{l}\text { A2: Drug price effect induction level } \\
\text { equalization }\end{array}$ & $\begin{array}{l}\text { 17: The percentage of drug expenditure out of } \\
\text { household disposable income }\end{array}$ & 0.2664 \\
\hline & & $\begin{array}{l}\text { 18: Drug expenditure spent in public health } \\
\text { institutions }\end{array}$ & 0.2518 \\
\hline & & 19: Drug expenditure spent in retail pharmacies & 0.1275 \\
\hline & & $\begin{array}{l}\text { 110: Drug expenditure spent in online } \\
\text { pharmacies }\end{array}$ & 0.0203 \\
\hline & & $\begin{array}{l}\text { 111: The percentage of outpatient drug } \\
\text { expenses }\end{array}$ & 0.1956 \\
\hline & & $\begin{array}{l}\text { 112: The percentage of hospitalization drug } \\
\text { expenses }\end{array}$ & 0.1384 \\
\hline & A3: Drug fair effect induction level equalization & $\begin{array}{l}\text { I13: Medical insurance reimbursement level of } \\
\text { medical expenses }\end{array}$ & 0.2732 \\
\hline & & $\begin{array}{l}\text { 114: Second reimbursement level of drug } \\
\text { expenses }\end{array}$ & 0.2537 \\
\hline & & I15: Level of self-paying drug affordability & 0.2177 \\
\hline & & I16: Resident satisfaction of prescriptions & 0.0725 \\
\hline & A4: Drug health effect induction level & 117: EQ-5D-5L rating scale & 0.6896 \\
\hline & equalization & |18: BMI & 0.3104 \\
\hline
\end{tabular}

sampling formula to calculate the sample size of chronic disease patients in four provinces, because we only had limited literature and more parameters were needed in the stratified sample size calculation formula (24). After we got the total sample needed, we allocated the sample size in selected hospitals using probability proportionate to size sampling (PPS) (25).

The simple random size calculation formula (26):

$$
N=\frac{Z_{\alpha}^{2} * \pi(1-\pi)}{E^{2}}
$$

Let $\mathrm{E}=0.05, \mathrm{Z}=1.96, \alpha=0.05, \pi(1-\pi)=0.5$. Taking incomplete questionnaires into account, we should survey about 384 chronic disease patients. Obviously, the sample size of this study meets the requirements.

This study used SPSS 22.0 software to summarize the results of the 963 questionnaires collected and performed reliability and validity analysis. The results of the study showed that the Cronbach's $\alpha$ value of the 18 evaluation indicators involving the equalization of drug welfare induction in patients with chronic diseases was 0.733 , and the Cronbach's $\alpha$ value based on the standardized project was 0.741 , both of which were $>0.7$. Therefore, the questionnaire indicators may be considered to have high validity. The KMO value was 0.791 , and the $p<0.001$, further indicating that the questionnaire was valid.

\section{Measurements}

We first use the weighted summation method to evaluate the level of equalization. Then the bivariate Theil-T index is used to decompose it hierarchically. Through layer decomposition, we can examine the overall difference structure from different perspectives. The contribution rate of the intra-group gap and the inter-group gap to the total gap can better understand the current equalization of the drug welfare level of chronic disease patients in China. See Figure 1 for details.

\section{Theil Index: Definition and Decomposition}

The statistical methods commonly used to measure the level of equalization of pharmaceutical welfare (public service) include the coefficient of variation method, the Gini coefficient method, and the Theil index method. All of the above methods can provide relatively scientific reference results to a certain extent, but it is difficult to accurately reflect the difference in the level of urban-rural equalization or the difference between urban and rural areas. Compared with other equalization measurement tools, the Theil index has obvious technical advantages: First, 


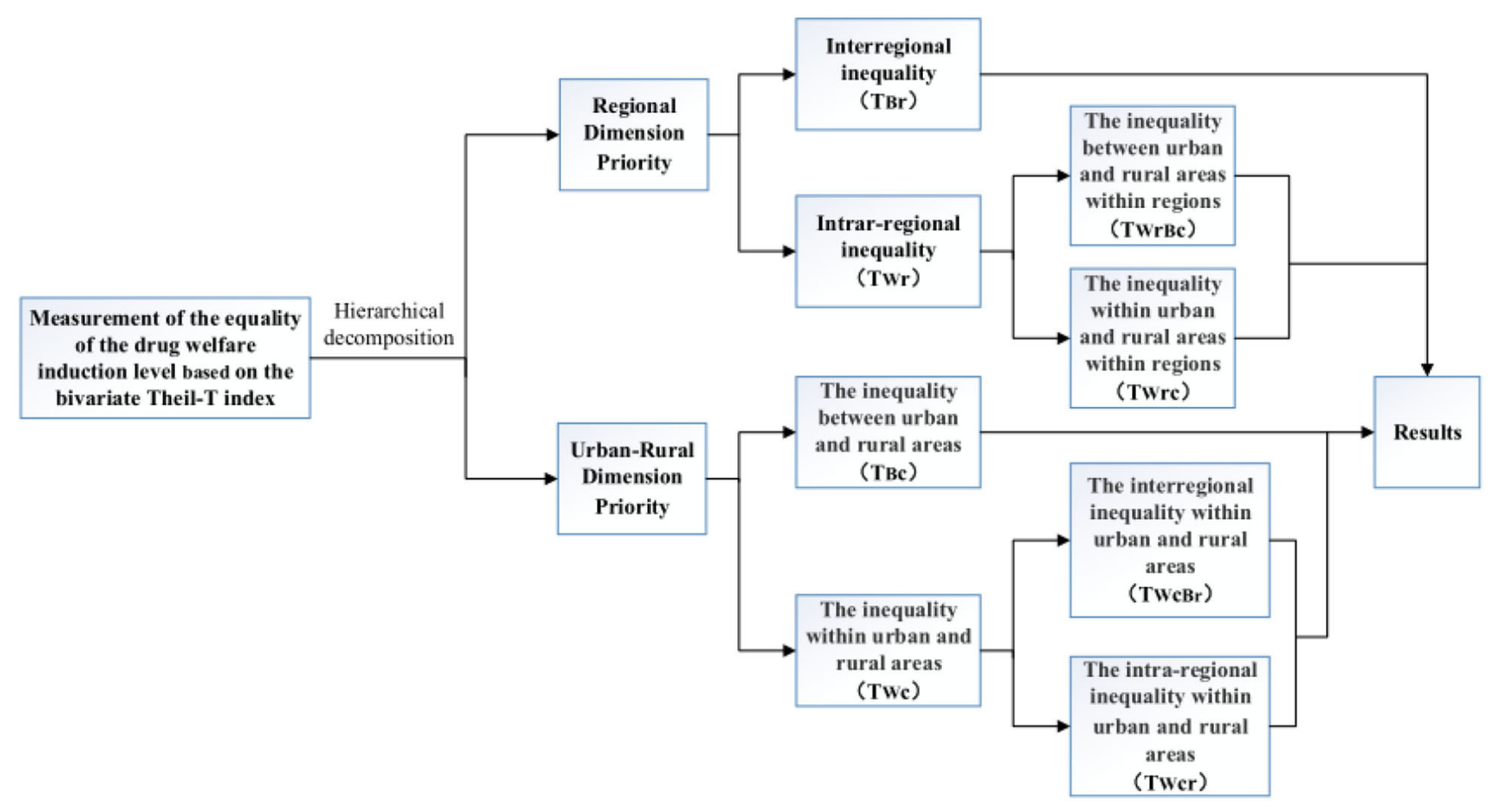

FIGURE 1 | Decomposition of bivariate Theil-T index of drug welfare induction level in patients with chronic diseases.

compared with the Gini coefficient equalization measurement tool, the Theil index equalization measurement tool is more laterally reorganized in the analysis process. The problem of decomposability emphasizes the degree of equalization of the population according to different group criteria. Second, compared with the equalization measurement tool of the coefficient of variation, the measurement index of the Theil index equalization can achieve unevenness in the measurement process. Steady reduction, more focused on the analysis of conduction sensitivity problems in the process of unequal (27).

The Theil $\mathrm{T}$ index (28) was used to quantify inequality at a district level. This index has been widely used to measure inequality in different health and social outcomes. For example, it has been used to measure income inequality in Latin America (29) or inequality in access to improved water in different world regions (30). Theil- $\mathrm{T}$ is a population weighted index that is sensitive to health differences further from the average rate (31).

In China, urban-rural differences and regional differences are large, and the use of the bivariate Theil index has innovative practical significance. At the same time, combining the two variables can examine the combined effect of the two on the level of equalization. Based on comprehensive considerations, this paper uses the bivariate Theil- $\mathrm{T}$ index in the Theil index equalization measurement tool to equalize the drug welfare induction level of chronic disease patients in China.

Due to its decomposability, the Theil index can be decomposed by intraregional differences and interregional differences, thereby measuring the contribution of intraregional differences and interregional differences to the total differences
(32-36). For this study, the Theil-T index refers to the degree of unequal distribution of drug welfare in patients with chronic diseases in different regions or in urban or rural areas relative to the population, that is, the perceived degree of unequal drug welfare per capita.

\section{Bivariate Theil-T Index With Regional Dimension Priority}

The bivariate Theil-T index adopts with priority to the regional dimension; that is, all the unequal indicators expressed by the Theil index are first decomposed according to the regional dimension. The first level is decomposed into interregional inequality (between western region and eastern region) and intraregional inequality (within western region or within eastern region). At the second level, the intra-regional inequality is decomposed into the inequality between urban and rural areas within regions, and the inequality within urban and rural areas within regions $(37,38)$, which is shown in Figure 2.

This paper uses four provinces of China (Gansu Province, Sichuan Province, Hebei Province, Zhejiang Province) as the basic research unit. The four provinces are divided into two groups according to geographical regions: the western region and the eastern region. The provinces included in each region are shown in Table 2.

Accordingly, the bivariate Theil-T index with hierarchical decomposition, giving priority to the regional dimension, is expressed as follows (39): 


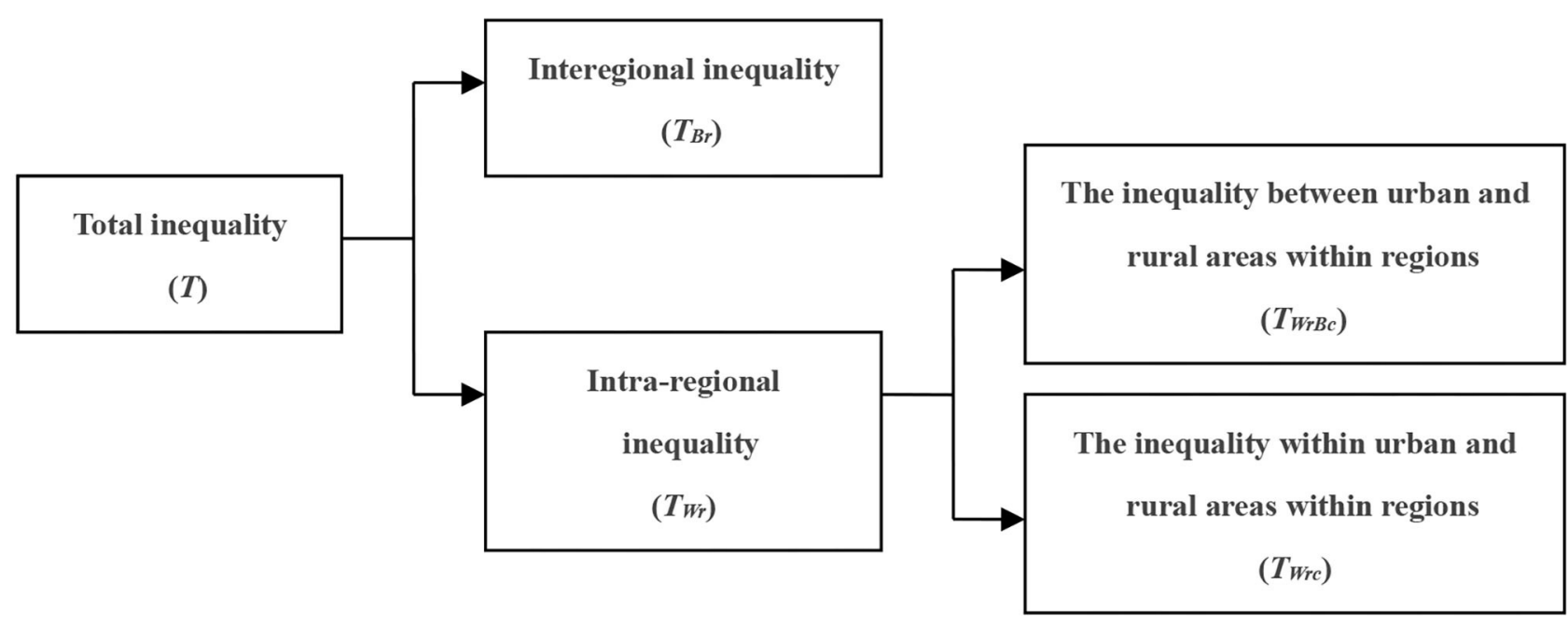

FIGURE 2 | Decomposition diagram along the regional dimension.

TABLE 2 | The two major regional divisions of China and representative provinces included.

\begin{tabular}{ll}
\hline Region & Representative provinces \\
\hline Western region & $\begin{array}{l}\text { Gansu, Sichuan } \\
\text { Hebei, Zhejiang }\end{array}$ \\
\hline
\end{tabular}

$$
\begin{aligned}
& T=T_{B_{r}}+T_{W_{r}}=T_{B_{r}}+T_{W_{r} B_{c}}+T_{W_{r c}} \\
& =\sum_{r}\left(\frac{Y_{r}}{Y} \log \frac{Y_{r} / Y}{N_{r} / N}\right)+\sum_{r}\left(\frac{Y_{r}}{Y}\left(\sum_{c}\left(\frac{Y_{r c}}{Y_{r}} \log \frac{Y_{r c} / Y_{r}}{N_{r c} / N_{r}}\right)\right)\right) \\
& +\sum_{r} \sum_{c}\left(\frac{Y_{r c}}{Y}\left(\sum_{i}\left(\frac{Y_{r c i}}{Y_{r c}} \log \frac{Y_{r c i} / Y_{r c}}{N_{r c i} / N_{r c}}\right)\right)\right)
\end{aligned}
$$

(Formula1)

where $T$ is the total Theil index, which measures the overall degree of inequality; $T_{B r}$ and $T_{W r}$, respectively, indicate the degree of inequality of drug welfare induction in patients with chronic diseases among and within regions; $T_{W r B c}$ and $T_{W r c}$, respectively, indicate the degree of inequality of drug welfare induction in patients with chronic diseases between urban and rural areas and between provinces and towns; $r, c$, and $i$, respectively, represent the regional grouping (east and west), urban and rural, and provinces in the $r$ region (Gansu Province, Sichuan Province, Hebei Province, and Zhejiang Province), total population of the sample area of the $N_{r c i}$ representative group, and total level of drug welfare induction of the patients with chronic diseases in the sample area of the $Y_{r c i}$ representative group, where:

$$
\begin{aligned}
N_{r}=\sum_{c} N_{r c}, N_{r c} & =\sum_{i} N_{r c i}, Y_{r}=\sum_{c} Y_{r c}, Y_{r c}=\sum_{i} Y_{r c i}, Y \\
& =\sum_{r} \sum_{c} \sum_{i} Y_{r c i}, N=\sum_{r} \sum_{c} \sum_{i} N_{r c i} .
\end{aligned}
$$

The values of the five indicators $T, T_{B r}, T_{B c}, T_{W r c}$, and $T_{I r c} \mathrm{c}$ are between 0 and 1 . The larger the value is, the lower the degree of equalization. The smaller the value is, the higher the degree of equalization.

\section{Bivariate Theil-T Index of Urban-Rural Dimension Priority}

This decomposition method uses the Theil index method to measure the equalization of drug welfare in patients with chronic diseases. At the first level, the decomposition concerns the inequality between urban and rural areas and the inequality within urban and rural areas. At the second level, the inequality within urban and rural areas is decomposed into the interregional inequality within urban and rural areas and the intra-regional inequality within urban and rural areas, as shown in Figure 3.

Thus, the bivariate Theil-T exponential decomposition formula that prioritizes the urban-rural dimensions is:

$$
\begin{aligned}
& T=T_{B_{c}}+T_{W_{c}}=T_{B_{c}}+T_{W_{c} B_{r}}+T_{W_{c r}} \\
& =\sum_{c}\left(\frac{Y_{c}}{Y} \log \frac{Y_{c} / Y}{N_{c} / N}\right)+\sum_{c}\left(\frac{Y_{c}}{Y}\left(\sum_{r}\left(\frac{Y_{c r}}{Y_{c}} \log \frac{Y_{c r} / Y_{c}}{N_{c r} / N_{c}}\right)\right)\right) \text { (Formula 2) } \\
& +\sum_{c} \sum_{r}\left(\frac{Y_{c r}}{Y}\left(\sum_{i}\left(\frac{Y_{c r i}}{Y_{c r}} \log \frac{Y_{c r i} / Y_{c r}}{N_{c r i} / N_{c r}}\right)\right)\right)
\end{aligned}
$$

where $T_{B c}$ and $T_{W c}$ indicate the degree of inequality of drug welfare in patients with chronic diseases between urban and rural areas, respectively. $T_{W c B r}$ and $T_{W c r}$ indicate the degree of inequality of drug welfare of patients with chronic diseases in urban and rural areas in different regions, respectively. The other 


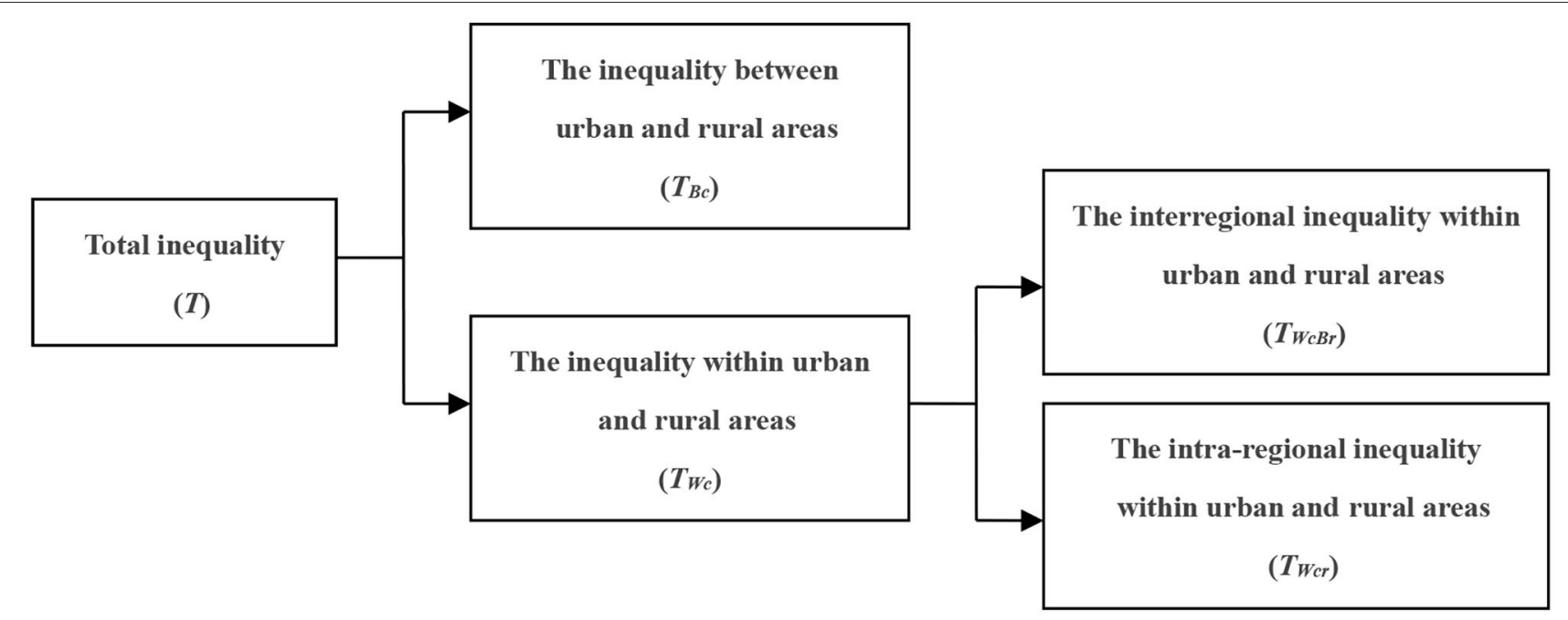

FIGURE 3 | Decomposition diagram along the urban and rural dimension.

variables have the same meaning as above. Thus,

$$
\begin{aligned}
& \mathbf{N}_{\mathrm{c}}=\sum_{\mathbf{r}} \mathbf{N}_{\mathrm{cr}}, \mathbf{N}_{\mathrm{cr}}=\sum_{\mathrm{i}} \mathbf{N}_{\mathrm{cri}}, \mathbf{Y}_{\mathrm{c}}=\sum_{\mathbf{r}} \mathbf{Y}_{\mathrm{cr}}, \mathbf{Y}_{\mathrm{cr}}=\sum_{\mathrm{i}} \mathbf{Y}_{\mathrm{cri}}, \\
& \mathbf{Y}=\sum_{\mathrm{c}} \sum_{\mathrm{r}} \sum_{\mathrm{i}} \mathbf{Y}_{\mathrm{cri}}, \mathbf{N}=\sum_{\mathrm{c}} \sum_{\mathrm{r}} \sum_{\mathrm{i}} \mathbf{N}_{\mathrm{cri}}
\end{aligned}
$$

\section{RESULTS}

\section{Bivariate Theil-T Index Hierarchical Decomposition Calculation of Drug Benefits in Patients With Chronic Diseases-The Regional Dimension}

By substituting the research data into formula 1, the hierarchical decomposition results of the bivariate Theil-T index with priority to the regional dimension can be obtained (see Table 3 ).

\section{The Regional Dimension Decomposition Results of the Total T-Values}

In this paper, the total $T$-value of the equalization of the drug welfare induction level in patients with chronic diseases is calculated as follows: total $T=0.0003$, which is close to 0 . Therefore, the level of the drug welfare response of Chinese patients with chronic diseases is relatively equal overall.

\section{The Regional Dimension Decomposition Results of the T-Values of Each Index}

After decomposing the $T$-value according to each indicator, the $T$-values of "I1: The number of medical service institutions that can be reached within 15 min," "I6: The expensive needed drug is not affordable" and "I14: Second reimbursement level of drug expenses" are higher than the other indicators, the values are $0.0050,0.0046$, and 0.0054 , respectively, and the $T$-values are all $>0.0040$ (see Figure 4), which means that the level of equalization of the drug welfare level of these three indicators is relatively low.

\section{The Results of the Internal Composition of the Interregional Inequality of the T-Values of Each Indicator}

In The internal composition of the interregional inequality, Table 3 lists the weighted logarithm of the mean value of the sensory level of the drug welfare indicators in the patients with chronic diseases in the eastern and western regions during the calculation of the $T$-value of the interregional inequality (the perceived level of welfare is proportional to the total level of welfare induction). Table 3 shows that except for the $T$-values of the indicator "I17: EQ-5D-5L" in the eastern and western regions, the $T$-values of indicators I1, I2, I4-I12, and I14 (see Table 1 for the meanings of the specific indicators, the same below) are all positive in the eastern region, suggesting that the level of drug welfare induction of patients with chronic diseases in the eastern region is at a high level as measured by these indicators. That is, the level of drug welfare induction of patients with chronic diseases in the eastern region is higher than the national average for these indicators. The opposite is found for the indicators above in the western region, and all of their values are negative, indicating that patients with chronic diseases in the western region have less than the national average level of welfare induction in terms of these indicators and therefore a low level of welfare.

\section{The Internal Decomposition Results of the Intra-Regional Inequality of the T-Values of Each Indicator}

In the decomposition of intra-regional disparity, the secondorder decomposition of the urban and rural dimensions of the indicators "I1: The number of medical service institutions that can be reached within $15 \mathrm{~min}$," "I6: The expensive drug needed is not affordable," "I14: Satisfaction with the second reimbursement level for drug expenses," and "I16: Satisfaction with the rationality of prescriptions by medical institutions" is different from that of the other indicators in the inequality within urban and rural 
TABLE 3 | Theil index decomposition results of perceived drug welfare level in patients with chronic diseases with regional dimension priority.

\begin{tabular}{|c|c|c|c|c|c|c|c|c|c|c|c|c|c|c|c|c|c|c|c|}
\hline & 11 & 12 & 13 & 14 & 15 & 16 & 17 & 18 & 19 & 110 & 111 & 112 & 113 & 114 & 115 & I16 & 117 & 118 & Total \\
\hline$T$ & 0.0050 & 0.0005 & 0.0004 & 0.0033 & 0.0033 & 0.0046 & 0.0016 & 0.0009 & 0.0004 & 0.0013 & 0.0010 & 0.0007 & 0.0016 & 0.0054 & 0.0025 & 0.0016 & 0.0002 & 0.0001 & 0.0003 \\
\hline$T_{B r}$ & 0.0000 & 0.0000 & 0.0002 & 0.0010 & 0.0007 & 0.0015 & 0.0000 & 0.0000 & 0.0000 & 0.0008 & 0.0001 & 0.0000 & 0.0000 & 0.0005 & 0.0000 & 0.0000 & 0.0000 & 0.0000 & 0.0001 \\
\hline $\begin{array}{l}\text { Weighted logarithm } \\
\text { (1) (western) }\end{array}$ & -0.0031 & -0.0018 & 0.0065 & -0.0143 & -0.0119 & -0.0174 & -0.0027 & -0.0029 & -0.0027 & -0.0126 & -0.0037 & -0.0003 & 0.0023 & -0.0099 & 0.0025 & 0.0001 & 0.0000 & 0.0021 & -0.0034 \\
\hline $\begin{array}{l}\text { Weighted logarithm } \\
\text { (eastern) }\end{array}$ & 0.0031 & 0.0018 & -0.0063 & 0.0153 & 0.0126 & 0.0189 & 0.0027 & 0.0029 & 0.0027 & 0.0133 & 0.0038 & 0.0003 & -0.0023 & 0.0104 & -0.0025 & -0.0001 & 0.0000 & -0.0020 & 0.0035 \\
\hline$T_{W_{r}}$ & 0.0049 & 0.0005 & 0.0002 & 0.0023 & 0.0026 & 0.0031 & 0.0016 & 0.0008 & 0.0004 & 0.0005 & 0.0009 & 0.0007 & 0.0016 & 0.0049 & 0.0025 & 0.0016 & 0.0002 & 0.0001 & 0.0002 \\
\hline$T_{W r B C}$ & 0.0023 & 0.0002 & 0.0001 & 0.0008 & 0.0000 & 0.0004 & 0.0003 & 0.0004 & 0.0001 & 0.0001 & 0.0003 & 0.0004 & 0.0007 & 0.0007 & 0.0008 & 0.0004 & 0.0001 & 0.0000 & 0.0001 \\
\hline $\begin{array}{l}\text { Urban and rural areas in the } \\
\text { western region }\end{array}$ & 0.0007 & 0.0002 & 0.0000 & 0.0008 & 0.0000 & 0.0002 & 0.0000 & 0.0004 & 0.0000 & 0.0001 & 0.0003 & 0.0003 & 0.0003 & 0.0003 & 0.0000 & 0.0004 & 0.0000 & 0.0000 & 0.0000 \\
\hline $\begin{array}{l}\text { Urban and rural areas in the } \\
\text { eastern region }\end{array}$ & 0.0016 & 0.0000 & 0.0001 & 0.0000 & 0.0000 & 0.0002 & 0.0003 & 0.0000 & 0.0000 & 0.0000 & 0.0001 & 0.0001 & 0.0004 & 0.0004 & 0.0008 & 0.0000 & 0.0001 & 0.0000 & 0.0001 \\
\hline$T_{\text {Wrc }}$ & 0.0026 & 0.0003 & 0.0001 & 0.0015 & 0.0026 & 0.0027 & 0.0013 & 0.0004 & 0.0003 & 0.0004 & 0.0006 & 0.0003 & 0.0009 & 0.0042 & 0.0016 & 0.0013 & 0.0000 & 0.0000 & 0.0002 \\
\hline Rural interior & 0.0023 & 0.0000 & 0.0001 & 0.0012 & 0.0011 & 0.0010 & 0.0013 & 0.0002 & 0.0001 & 0.0002 & 0.0002 & 0.0003 & 0.0007 & 0.0020 & 0.0011 & 0.0005 & 0.0000 & 0.0000 & 0.0000 \\
\hline $\begin{array}{l}\text { Rural interior of western } \\
\text { region }\end{array}$ & 0.0000 & 0.0000 & 0.0001 & 0.0009 & 0.0001 & 0.0005 & 0.0000 & 0.0000 & 0.0001 & 0.0000 & 0.0001 & 0.0001 & 0.0004 & 0.0000 & 0.0001 & 0.0000 & 0.0000 & 0.0000 & 0.0000 \\
\hline $\begin{array}{l}\text { Rural interior of eastern } \\
\text { region }\end{array}$ & 0.0023 & 0.0000 & 0.0000 & 0.0003 & 0.0010 & 0.0005 & 0.0012 & 0.0001 & 0.0000 & 0.0002 & 0.0001 & 0.0002 & 0.0003 & 0.0019 & 0.0010 & 0.0005 & 0.0000 & 0.0000 & 0.0000 \\
\hline Urban interior & 0.0003 & 0.0002 & 0.0000 & 0.0003 & 0.0015 & 0.0017 & 0.0001 & 0.0002 & 0.0002 & 0.0002 & 0.0004 & 0.0000 & 0.0002 & 0.0022 & 0.0006 & 0.0008 & 0.0000 & 0.0000 & 0.0001 \\
\hline $\begin{array}{l}\text { Urban interior of western } \\
\text { region }\end{array}$ & 0.0001 & 0.0001 & 0.0000 & 0.0000 & 0.0005 & 0.0011 & 0.0000 & 0.0002 & 0.0000 & 0.0000 & 0.0004 & 0.0000 & 0.0001 & 0.0001 & 0.0006 & 0.0003 & 0.0000 & 0.0000 & 0.0001 \\
\hline $\begin{array}{l}\text { Urban interior of eastern } \\
\text { region }\end{array}$ & 0.0002 & 0.0001 & 0.0000 & 0.0003 & 0.0010 & 0.0007 & 0.0000 & 0.0000 & 0.0002 & 0.0001 & 0.0000 & 0.0000 & 0.0001 & 0.0021 & 0.0000 & 0.0005 & 0.0000 & 0.0000 & 0.0000 \\
\hline The proportion of $T_{B r}(\%)$ & 0.90 & 3.32 & 49.41 & 30.12 & 20.92 & 32.83 & 2.13 & 4.63 & 7.79 & 59.46 & 6.41 & 0.06 & 1.55 & 8.86 & 1.16 & 0.00 & 0.00 & 25.91 & 18.53 \\
\hline The proportion of $T_{W_{r}}(\%)$ & 99.10 & 96.68 & 50.59 & 69.88 & 79.08 & 67.17 & 97.87 & 95.37 & 92.21 & 40.54 & 93.59 & 99.94 & 98.45 & 91.14 & 98.84 & 100.00 & 100.00 & 74.09 & 81.47 \\
\hline The proportion of $T_{W r B C}(\%)$ & 46.32 & 42.56 & 20.82 & 23.57 & 0.23 & 8.56 & 16.93 & 50.32 & 19.23 & 9.62 & 31.67 & 55.61 & 45.06 & 12.85 & 33.81 & 22.77 & 73.43 & 9.86 & 29.60 \\
\hline The proportion of $T_{\text {wrc }}(\%)$ & 52.78 & 54.12 & 29.77 & 46.31 & 78.85 & 58.61 & 80.94 & 45.05 & 72.98 & 30.92 & 61.92 & 44.33 & 53.39 & 78.29 & 65.03 & 77.23 & 26.57 & 64.23 & 51.86 \\
\hline
\end{tabular}

(1) This indicator is only the internal component of calculating the T-value of the inequality between groups. The value is positive or negative, which is different from the T value after summation. Referring to Huang Guoping (2012) (26), the value is rounded off, and the actual value is not zero, so the calculated contribution is not zero. (The table below is the same). 


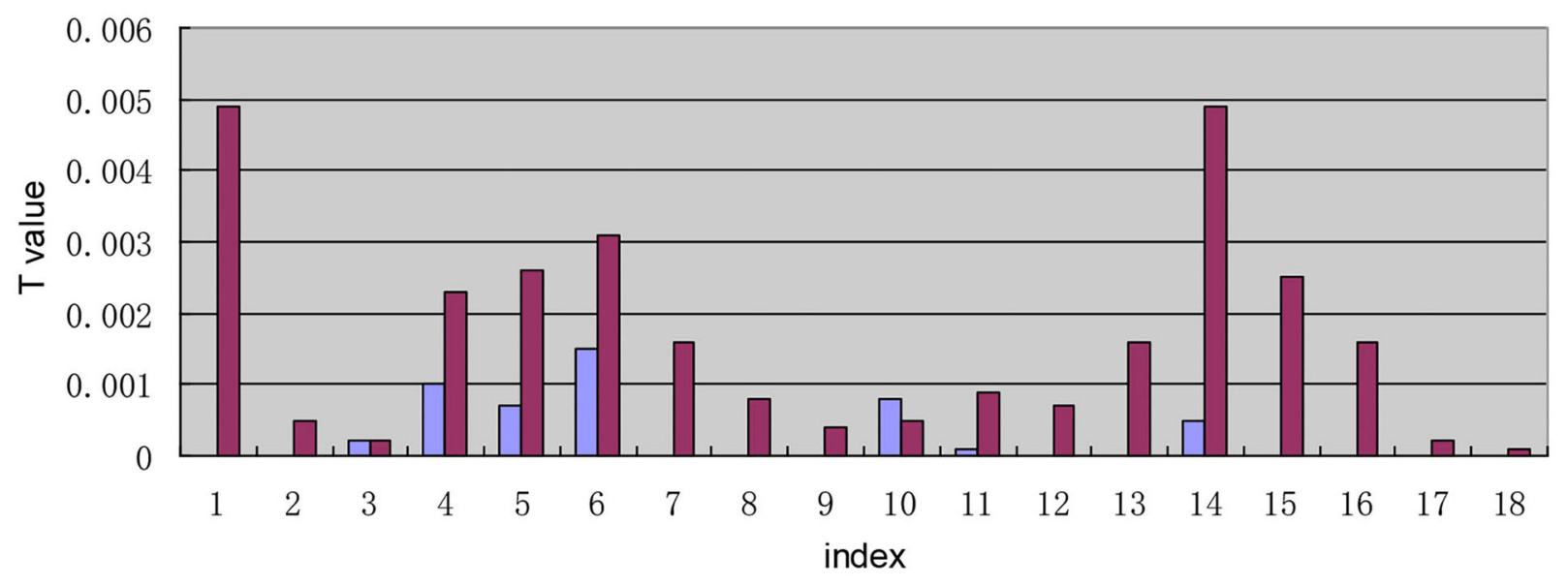

$\square \operatorname{TBr} \square \mathrm{TWr}$

FIGURE 4 | Decomposition of $T$-values of each indicator along the regional dimensional.

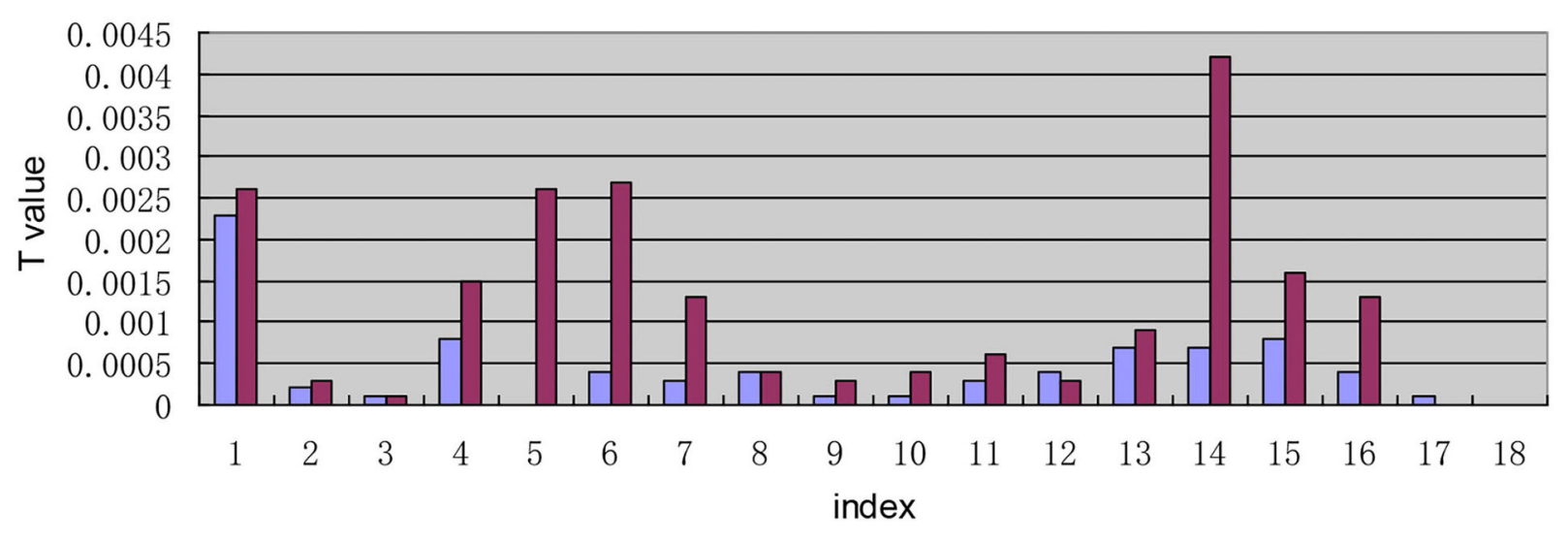

$\square$ TWrBc $\square$ TWrc

FIGURE 5 | Intra-regional inequality between each indicator decomposition based on the urban and rural dimension.

areas within regions, with $T_{W r c}$ values $>0.0020$. Moreover, the inequality within urban and rural areas within regions in these four indicators is larger than the inequality between urban and rural areas within regions (see Figure 5).

\section{Urban-Rural Dimension: First Bivariate Theil-T Index Hierarchical Decomposition Calculation}

By substituting relevant data into formula 2, the bidimensional hierarchical calculation results shown in Table 4 can be obtained. Compared with the decomposition of the bivariate Theil-T index with priority to the regional dimension, the internal composition of the bivariate Theil-T index with priority to the urban and rural dimension has changed.

\section{Regional Dimension Decomposition Results of Total T-Values}

The results of the total $T$-values obtained by the decomposition of the urban and rural dimension are the same as those obtained by the decomposition of the regional dimension.

\section{Decomposition Results of T-Values of Each Indicator Along the Urban-Rural Dimension}

After the first-order decomposition of each indicator along the urban-rural dimension, the comparison of $T$-values between urban-rural areas and within urban-rural areas shows that the $T$-values of I1, I4, I5, I6, and I14 of the equalization of drug and welfare response levels for Chinese patients with chronic diseases are significantly different from the values for other indicators. On the whole, China needs to increase the accessibility and fairness of drug distribution in terms of 
TABLE 4 | Theil index decomposition results of drug welfare induction level of patients with chronic diseases in urban and rural areas.

\begin{tabular}{|c|c|c|c|c|c|c|c|c|c|c|c|c|c|c|c|c|c|c|c|}
\hline & 11 & 12 & 13 & 14 & 15 & 16 & 17 & 18 & 19 & 110 & 111 & 112 & 113 & 114 & 115 & I16 & 117 & 118 & Total \\
\hline$T$ & 0050 & 0005 & 0004 & 0.0033 & 0.0033 & 0.0046 & 0016 & 0009 & 0004 & 0013 & 0010 & 0007 & 0.0016 & 0.0054 & 0.0025 & 0.0016 & .0002 & .0001 & 0.0003 \\
\hline$T_{B C}$ & 0.0021 & 0.0000 & 0000 & 0.0003 & 0.0000 & 0.0004 & 0002 & 0001 & 0000 & 0.0001 & 0.0000 & 0000 & 0.0000 & 0.0000 & 0.0006 & 0.0002 & 0000 & .0000 & 0.0000 \\
\hline Weighted lo & 0.0225 & -0.0028 & 0.0015 & 0.0087 & 0.0002 & 0.0089 & 0.0067 & -0.0046 & -0.0004 & 0.0042 & -0.0030 & -0.0032 & 0.0004 & 0.0001 & 0.0112 & -0.0064 & -0.0025 & -0.0012 & 0.0017 \\
\hline Weighted logarithm (rural) & -0.0204 & 0.0029 & -0.0015 & -0.0084 & -0.0002 & -0.0086 & -0.0065 & 0.0047 & 0.0004 & -0.0041 & 0.0030 & 0.0032 & -0.0004 & -0.0001 & -0.0106 & 0.0066 & 0.0025 & 0.0012 & -0.0017 \\
\hline$T_{W c}$ & 0028 & 0.0004 & 0.0004 & 0.0030 & 0.0033 & 0.0042 & 0.0014 & 0.0008 & 0.0004 & 0.0012 & 0.0010 & 0.0007 & 0.0016 & 0.0054 & 0.0019 & 0.0014 & 0.0001 & 0.0001 & 0.0003 \\
\hline$T_{W C B r}$ & 0.0002 & 0.0002 & 0.0003 & 0.0015 & 0.0007 & 0.0016 & 0.0001 & 0.0004 & 0.0001 & 0.0008 & 0.0003 & 0.0004 & 0.0008 & 0.0012 & 0.0003 & 0.0002 & 0.0001 & 0.0000 & 0.0001 \\
\hline Interare & 0.0002 & 0.0001 & 0.0000 & 0.0001 & 0.0004 & 0.0008 & 0.0001 & 0.0003 & 0.0001 & 0.0003 & 0.0003 & 0.0002 & 0.0002 & 0.0012 & 0.0001 & 0.0001 & 0.0000 & 0.0000 & 0.0001 \\
\hline Interar & 0.0000 & 0.0000 & 0.0002 & 0.0014 & 0.0003 & 0.0007 & 0.0000 & 0.0001 & 0.0000 & 0.0005 & 0.0000 & 0.0002 & 0.0005 & 0.0000 & 0.0003 & 0.0001 & 0.0000 & 0.0000 & 0.0000 \\
\hline Twor & 0.0026 & 0.0003 & 0.0001 & 0.0015 & 0.0026 & 0.0027 & 0.0013 & 0.0004 & 0.0003 & 0.0004 & 0.0006 & 0.0003 & 0.0009 & 0.0042 & 0.0016 & 0.0013 & 0.0000 & 0.0000 & 0.0002 \\
\hline Easte & .0025 & 0.0002 & 0.0000 & 0.0006 & 0.0020 & 0.0011 & 0.0013 & 0.0001 & 0.0002 & 0.0003 & 0.0001 & 0.0002 & 0.0004 & 0.0040 & 0.0010 & 0.0010 & 0.0000 & 0.0000 & 0.0000 \\
\hline Eastern interior of urban areas & 0.0002 & 0.0001 & 0.0000 & 0.0003 & 0.0010 & 0.0007 & 0.0000 & 0.0000 & 0.0002 & 0.0001 & 0.0000 & 0.0000 & 0.0001 & 0.0021 & 0.0000 & 0.0005 & 0.0000 & 0.0000 & 0.0000 \\
\hline Eastern interior of rural areas & 0.0023 & 0.0000 & 0.0000 & 0.0003 & 0.0010 & 0.0005 & 0.0012 & 0.0001 & 0.0000 & 0.0002 & 0.0001 & 0.0002 & 0.0003 & 0.0019 & 0.0010 & 0.0005 & 0.0000 & 0.0000 & 0.0000 \\
\hline lestern interior & 0.0001 & 0.0001 & 0.0001 & 0.0009 & 0.0006 & 0.0016 & 0.0000 & 0.0002 & 0.0002 & 0.0001 & 0.0005 & 0.0001 & 0.0005 & 0.0002 & 0.0006 & 0.0003 & 0.0000 & 0.0000 & 0.0001 \\
\hline Western interior of urban areas & 0.0001 & 0.0001 & 0.0000 & 0.0000 & 0.0005 & 0.0011 & 0.0000 & 0.0002 & 0.0000 & 0.0000 & 0.0004 & 0.0000 & 0.0001 & 0.0001 & 0.0006 & 0.0003 & 0.0000 & 0.0000 & 0.0001 \\
\hline interior of rural areas & 0.0000 & 0.0000 & 0.0001 & 0.0009 & 0.0001 & 0.0005 & 0.0000 & 0.0000 & 0.0001 & 0.0000 & 0.0001 & 0.0001 & 0.0004 & 0.0000 & 0.0001 & 0.0000 & 0.0000 & 0.0000 & 0.0000 \\
\hline The proportion of $T_{B C}(\%)$ & 43.14 & 8.02 & 2.54 & 10.14 & 0.00 & 7.72 & 12.33 & 11.67 & 0.16 & 6.11 & 4.22 & 6.41 & 0.04 & 0.00 & 22.03 & 12.01 & 17.50 & 8.88 & 4.26 \\
\hline The proportion of $T_{w_{c}}(\%)$ & 56.86 & 91.98 & 97.46 & 89.86 & 100.00 & 92.28 & 87.67 & 88.33 & 99.84 & 93.89 & 95.78 & 93.59 & 99.96 & 100.00 & 77.97 & 87.99 & 82.50 & 91.12 & 95.74 \\
\hline The proportion of $T_{W_{C B C}}(\%)$ & 4.08 & 37.86 & 67.69 & 43.55 & 21.15 & 33.68 & 6.73 & 43.28 & 26.85 & 62.97 & 33.87 & 49.26 & 46.57 & 21.71 & 12.94 & 10.76 & 55.93 & 26.89 & 43.88 \\
\hline The proportion o & 2.78 & .12 & 29.77 & 46.31 & 78.85 & 8.61 & 0.94 & 45.05 & 72.98 & 30.92 & 1.92 & 4.33 & 3.39 & 78.29 & 65.03 & 77.23 & 26.57 & 4.23 & 51.86 \\
\hline
\end{tabular}


improving the level of drug welfare of patients with chronic diseases, especially in terms of the accessibility of medicines. Furthermore, in addition to the two indicators of I17 and I18, the inequality within urban and rural areas in the remaining indicators is larger than that between urban and rural areas. A visual comparison of the inequality between urban and rural areas and the inequality within urban and rural areas is shown in Figure 6.

\section{Internal Composition of the Inequality Between Urban and Rural Areas}

In the internal composition of the inequality between urban and rural areas, Table 4 lists the weighted log values of the deviation of the induction level from the average value of all indicators in the process of calculating the $T$-value of the inequality between urban and rural areas. In the composition of the $T_{B C}$ value, the urban component value of indicators I1, I3-I7, I10, and I13-15 is positive, while the rural component value is negative, indicating that these indicators are low in the rural area. The urban component value of indicators I2, I8, I9, I11, I12, and I16-I18 is negative, while the rural component value is positive. Therefore, these indicators are at a low level in cities.

\section{The Internal Composition of the Inequality Within Urban and Rural Areas}

In the composition of the inequality within urban and rural areas, the intra-regional inequality within urban and rural areas found for indicators I1, I5, I6, and I14 are significantly higher than those the interregional inequality within urban and rural areas (see Figure 7). Further analysis of the interregional inequality within urban and rural areas shows that the inequality between rural areas for the five indicators of I3, I4, I10, I13, and I15 is larger than that between urban areas (see Figure 8).

Meanwhile, It can be seen from the composition of the intraregional inequality within urban and rural areas (Figure 9) that the indicators "I1: satisfaction with the number of medical and health service institutions within $15 \mathrm{~min}$," "I7: proportion of drug expenditure in household disposable income," and "I15: affordable level of out-of-pocket drug expenses" show a large inequality in rural areas in eastern China. For indicators "I4: the inequality between rural areas in western China is large when the required drug is available in online drug stores," "I5: unavailability of cheap drug needed," and "I14: satisfaction with the level of secondary reimbursement of drug costs," the rural-eastern internal inequality is similar to the urban-eastern internal inequality, and the inequality is larger than that for other indicators. Indicator "I6: The expensive drug needed is not affordable" shows a large inequality in the urban areas in the western region. The reasons for the above phenomenon are mainly found in two aspects: on one hand, the disparity of economic development level among provinces in the region is still large; on the other hand, local governments pay different levels of attention to drug welfare and support it in different ways. While the state is committed to solving the inequality of drug welfare between urban and rural areas, it pays insufficient attention to the intra-regional inequality within urban and rural areas.

\section{DISCUSSION}

In this study, we construct an indicator system to measure the drug welfare induction level of patients with chronic diseases in China. We use the bivariate Theil index for hierarchical decomposition to empirically analyze the samples of four provinces under investigation and find out the differential structure of the drug welfare induction level of patients with chronic diseases from the regional dimension and the urbanrural dimension.

In the decomposition results of both regional dimension priority and urban-rural dimension priority, the total $\mathrm{T}$ value of the drug welfare induction level is 0.0003 , which is close to 0 , indicating the overall induction level is relatively equal. This shows that the differences of chronic disease drug management and health services in China are not great as a whole. There is not much difference in the medication situation of patients, which is similar to the conclusions of previous studies: The vast majority of $\mathrm{CNCD}$ patients do not receive proper care, and more than $70 \%$ of CNCD patients are not well-controlled (40). From 2010 to 2014, the gap of self-rated health between different income groups in China had been narrowed and health equity had been improved (41).

\section{Bivariate Theil-T Index With Regional Dimension Priority}

The hierarchical decomposition of the Theil index with priority in the regional dimension shows that the intra-regional (eastern region interior or western region interior) gap of the drug welfare induction level of patients with chronic diseases in China is larger than the inter-regional (between eastern and western regions) gap. This is because China's current poverty alleviation policies for health in the west have gradually narrowed the gap between regions. For example, the government has increased the proportion of subsidies to the central and western regions and remote and poor areas when arranging subsidy funds for public health and resident medical insurance; it also has implemented special subsidies for poor areas and focused on improving the medical and health service capabilities of the central and western regions. Unlike previous conclusions, previous studies have shown that there are significant regional differences in the distribution of health resources in China (42). The $T$-value of the index I1 is $>0.0040$ and 0.0020 after the first decomposition and the second decomposition, respectively, indicating that the level of induction of chronic disease patients represented by this index is relatively low. In other words, the degree of equalization of access to medical and health institutions is not high. It is worth noting that in the primary and secondary decomposition results of the regional dimension priority, the $T$ values of indicators I6 and I14 are larger than that of others, indicating that patients' induction of the affordability of highpriced drugs and the fairness of secondary reimbursement of drug costs is quite unbalanced. Previous studies have shown that in terms of per capita consumption capacity, the price of new anticancer drugs is unaffordable in China (43).

In terms of the internal composition of the inter-regional gap, patients with chronic diseases in the eastern region have a 


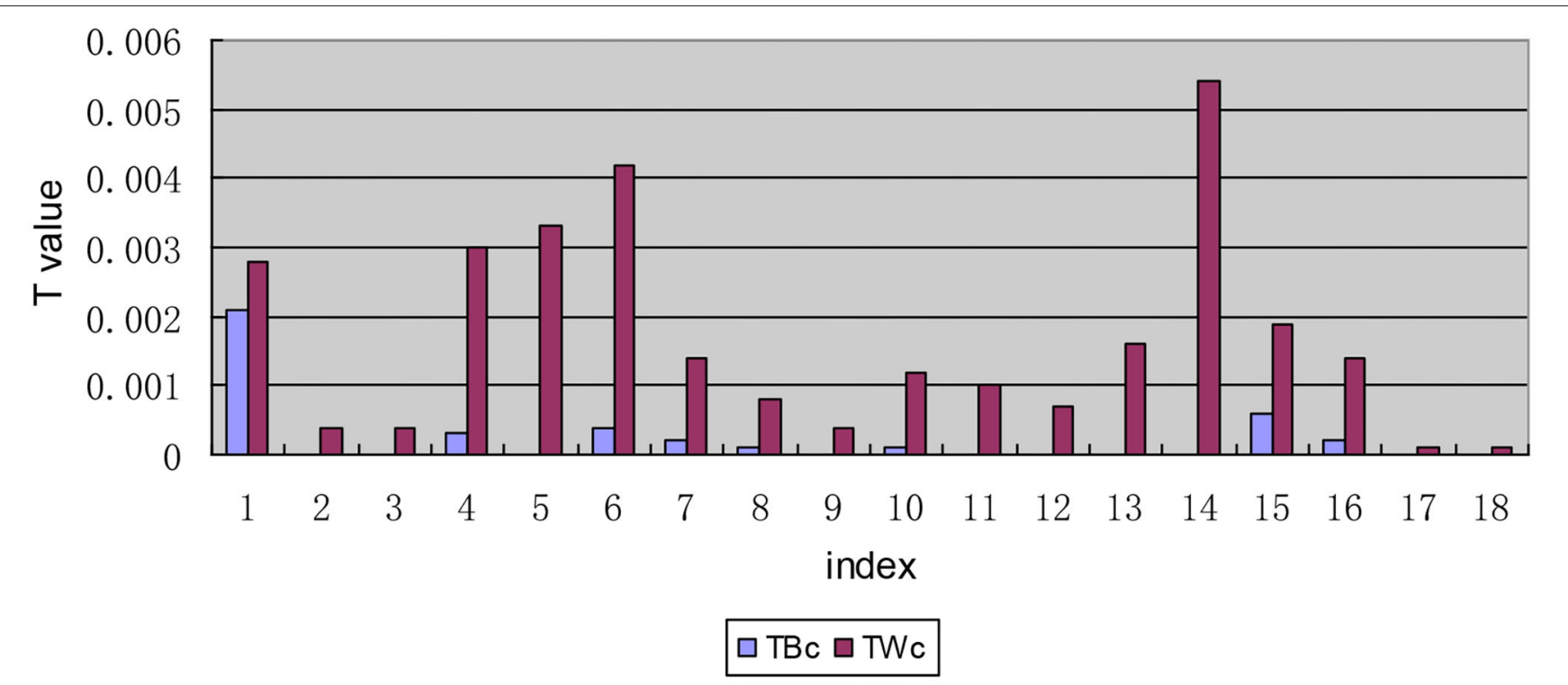

FIGURE 6 | Decomposition of T-values of each indicator along the urban and rural dimension.

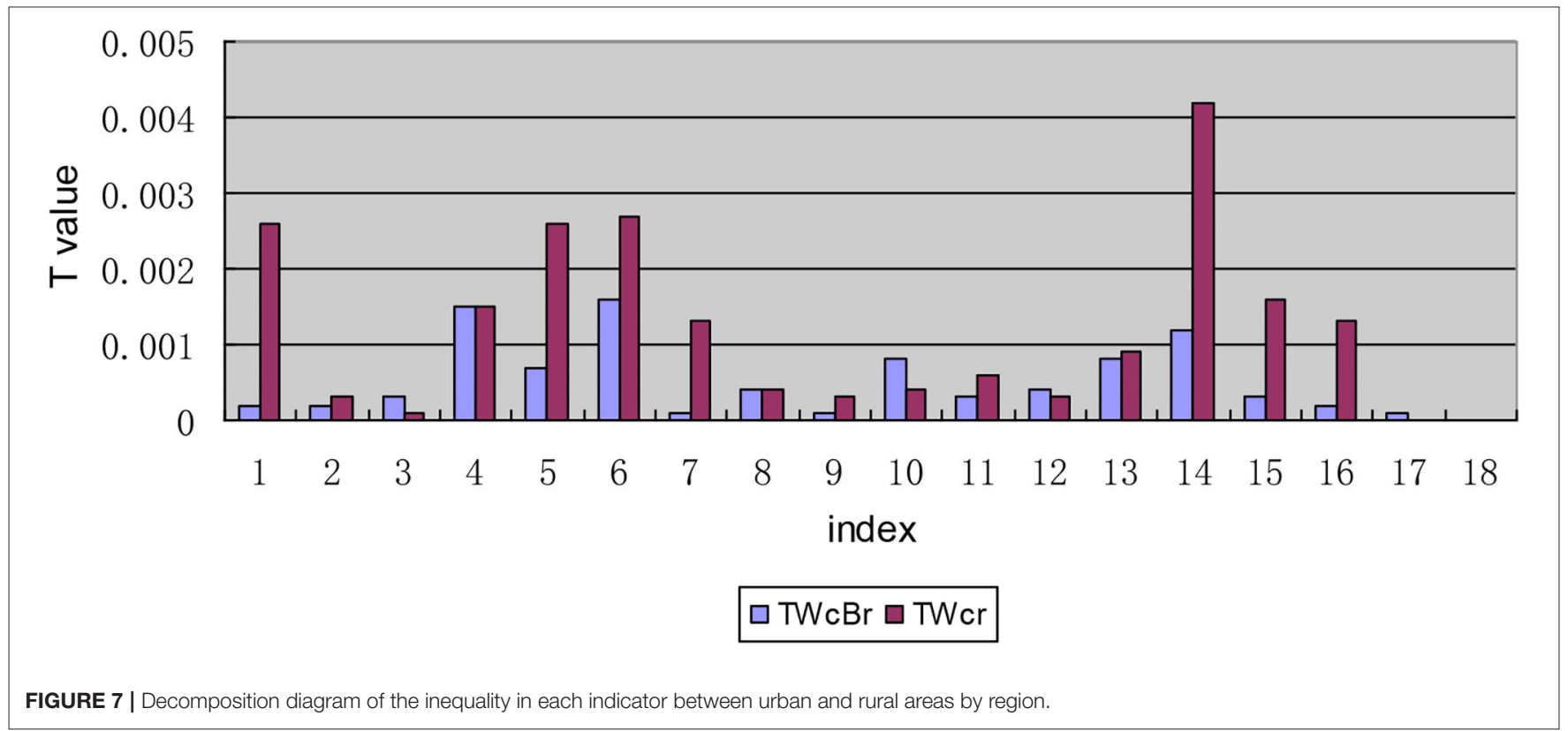

higher level of drug welfare induction, which is consistent with national conditions and related research results (44). The eastern region is economically developed, and the medical insurance fund guarantee is fundamentally stronger than that of the western region. Even if the western region has the support of Health Poverty Alleviation Policy, there is an imbalance in the drug welfare of patients with chronic diseases between the east and west of China, and there is a certain gap.

The price of medicine has always been a major issue related to the national economy and people's livelihood. In recent years, the Chinese government has made tremendous efforts to reduce drug prices and achieved certain results. For example, a series of comprehensive policies have been implemented, including "zero tariffs on imported anti-cancer drugs," "consistency evaluation and quality evaluation of generic drugs," " $4+7$ ” centralized drug procurement," and "zero-profit drug policy." These measures reduce the intermediate links of drug circulation, saving a lot of costs in promotion, distribution and other links, and reduce drug prices to the greatest extent. These drug policies have something in common with other countries: the US federal and state policies on generic drugs have reduced consumer spending; the combined drug procurement program of federal agencies will reduce the average cost sharing of Medicare beneficiaries $(45,46)$. However, the above-mentioned policies also bring some hidden 


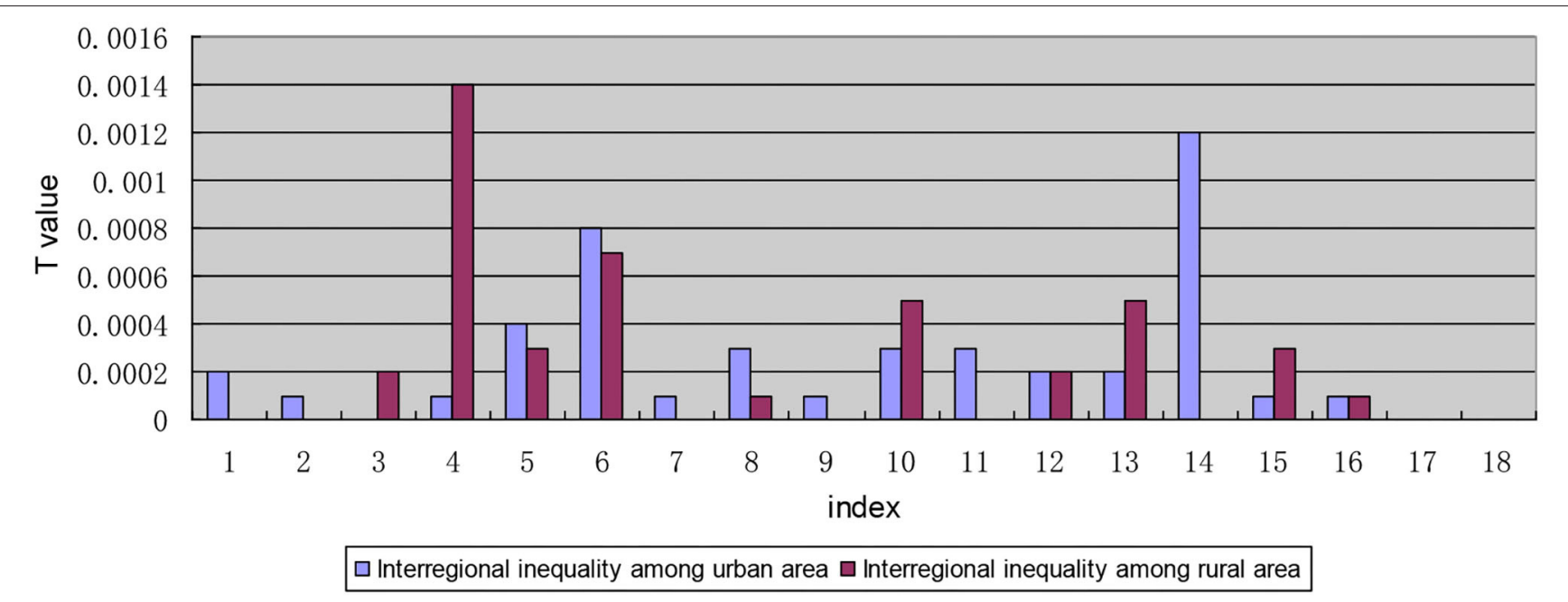

FIGURE 8 | Internal composition of the interregional inequality for each indicator within urban and rural areas.

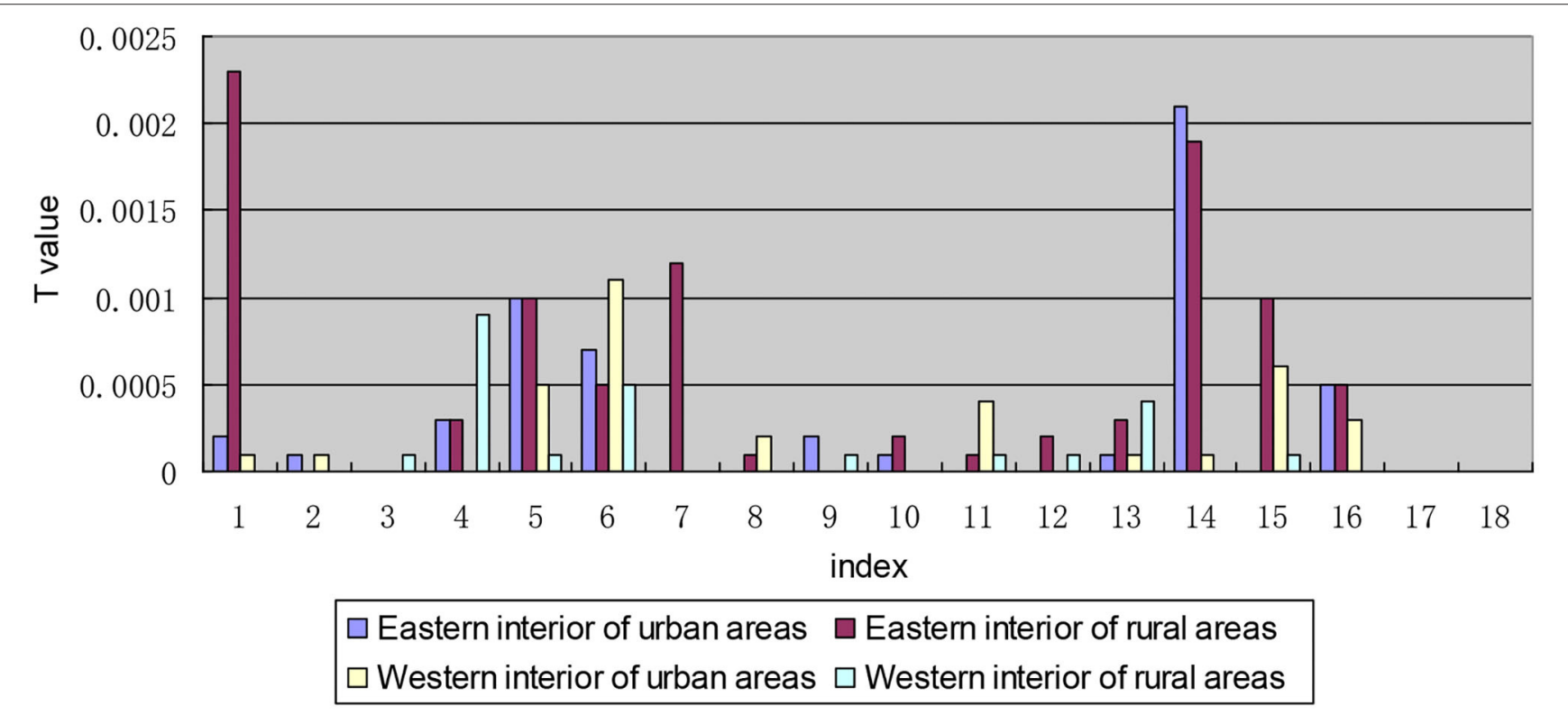

FIGURE 9 | Internal composition of the intra-regional inequality within urban and rural areas.

worries, such as the risk that the burden of patients' medical expenses and the burden of medical insurance fund expenditures will not decrease but increase (47). Through field investigations and empirical analysis, it is found that the current situation of unaffordable high-priced drugs is still grim in both urban and rural areas in China.

\section{Bivariate Theil-T Index With Urban-Rural Dimension Priority}

The hierarchical decomposition of Theil index with priority in the urban-rural dimension shows that the inequality within urban and rural areas in patients' drug welfare induction is much larger than that between urban and rural areas.
The contribution rate of the gap within urban and rural areas accounts for $95.74 \%$, which is the main aspect of the inequality of drug welfare for patients with chronic diseases. Early research found that compared with eastern and central regions, the medical and health burdens of farmers in western China (11 provinces and regions) were gradual (48). In particular, the degree of medical equalization in the eastern rural areas is relatively low, which is mainly reflected in the accessibility of medical institutions, the affordability of self-paid drugs, and the proportion of drug expenditures to household disposable income.

The first-order decomposition results show that the gap within urban and rural areas is greater than the gap between urban 
and rural areas. Although the country is committed to solving the problem of drug inequality between urban and rural areas, it has not paid enough attention to inequality within urban and rural areas. By addressing health inequality and creating a healthy social environment, China will be able to better cope with the heavy burden of chronic diseases (49). The accessibility of medicines represented by indicators I1, I4, I5, and I6 and the fairness of medicines represented by index I14 have a low degree of equalization. It can be seen that the problem of accessibility of medicines is the main aspect of the inequality of drug welfare. Timely and adequate supply of medicines is a difficulty faced by chronically ill patients in rural areas in China. However, under the severe burden of disease, "patients are poor because of diseases, and patients go back into poverty because of diseases." The composition of the inequality within urban and rural areas shows that the intra-regional inequality in drug welfare for patients with chronic diseases is greater than interregional inequality regardless of whether it is within cities or rural areas. The internal inequality in the west is greater than that in the east, which are mainly embodied in the accessibility of medicines. This is also due to the large gap in the economic development level of the provinces within the region. The low drug welfare in western China is mainly manifested in the poor accessibility of online drugs, which is related to the backward rural economy, lower Internet penetration rate, older chronic disease patients, lower education level, and less popularity of network usage. And it is more difficult to distribute drugs in the western region than that in the eastern region.

\section{Policy Implications}

Based on the above analysis, we seriously recommend that drug policy makers consider our results and formulate relevant intervention measures to improve the level of equalization of drug welfare for patients with chronic diseases.

First of all, in the face of poor affordability of high-priced drugs for chronic disease patients (I6), and whether in urban or rural areas, the intra-regional inequality is significantly larger than the inter-regional inequality, strong medical reform measures should be taken to strengthen the price regulation of commonly used drugs and high-priced drugs. In fact, there are inequalities in drug welfare in all regions of the country, and as far as western provinces are concerned, the driving force of medical insurance policies on the drug welfare of local patients with chronic diseases is also different. The National Healthcare Security Administration, which is directly under the State Council, was established in 2018, avoiding the problem of "decentralized functions" in the past. It enhances the coordination and leadership of medical reform, enabling medical insurance to act as a payer to leverage the transformation of medical service models and forces the reform of the pharmaceutical industry system. A series of policies such as medical insurance fund supervision, mass purchase, medical insurance catalog adjustment, DRG (Diagnosis Related Groups) payment, etc. ensure patients' high-priced drug use, great reduction of the economic burden of patients, improvement of public health, and creation of economic value (50).

Second, in order to ensure the supply of cheap drugs (I5) and the quality and level of medications for patients with chronic diseases, the production and supply guarantee mechanism for cheap drugs should be improved to promote the equalization of cheap drugs in urban and rural areas. Studies have shown that although the industries in developing countries are booming, the poor still cannot afford drugs (51), so the government should ensure the supply of cheap drugs, such as generic drugs (50). On the one hand, the shortage of cheap drugs is due to the low-price drug bidding system, which causes all links of the supply chain to lose production and sales momentum due to lack of profit; On the other hand, the raw materials are stockpiled and scarce, companies that successfully won the bid can only reduce costs, leading to a decline in drug quality. The shortage of cheap medicines at the grassroots level has a major impact on chronically ill patients and doctors (52). Therefore, it is necessary to establish a safety early warning and emergency management mechanism for drug supply.

Third, the government should establish a public health insurance budget system to promote the equalization of secondary drug reimbursements in urban and rural areas (53). Through the above empirical research, it is found that the level of secondary reimbursement of drug expenses for patients in China is still unequal. It is suggested that the existing decentralized basic medical security system be integrated into the provincebased single payment system through the reorganization of the financing system, payment structure, and operation mode (54). The government can also promote Urban and Rural Residents' Serious Illness Insurance Livelihood Project, and magnify the superimposed effects and security guarantee effects of various security systems to eliminate the phenomenon of "Poverty due to illness." In addition, in order to effectively improve the drug welfare of patients with chronic diseases and reduce the burden of outpatient drug costs for patients with hypertension, diabetes, etc., the National Medical Insurance Bureau should establish a complete outpatient medical expenses mutual assistance mechanism and include outpatient medical expenses into the payment scope of the basic medical insurance coordinating fund.

Fourth, the government should strengthen the standardized management of online pharmacies (55) to improve the efficiency of real-time supervision and to enhance patients trust in Internet drug platforms. Previous studies have shown that purchasing drugs from online pharmacies can improve the accessibility of drugs. However, due to the imperfect supervision system, the illegal sales of prescription drugs have been intensified. Therefore, it is necessary to strictly regulate online pharmacy sales practices (56). At the same time, this study finds that patients in rural areas in western China rarely buy drugs online, which is also related to the current Internet drug sales restrictions in China. Many drugs for the treatment of chronic diseases, such as cardiovascular and cerebrovascular drugs, are basically prescription drugs, while the drugs sold in online pharmacies can only be non-prescription drugs. At the same time, the medical insurance system cannot adapt to medical e-commerce payment, obliterating the convenience and price advantage of online drugs. The "Internet+" model should innovate according to the existing international mature model (57). It is strongly recommended that electronic prescription review methods be promoted in a timely manner and restrictions on online sales 
of prescription drugs be released on the basis of ensuring drug safety. In addition, the medical e-commerce should be covered by medical insurance system.

\section{Limitations and Future Research}

This study has some limitations. First, the patient's profile and environmental factors may vary geographically. Therefore, the environment of these four provinces may not represent all urban and rural areas in China. Second, the sensitivity level of drug welfare is easily affected by other factors, such as the regional economic system and the personal qualities of patients. Therefore, longitudinal studies with large sample sizes are expected to further explore the determinants that affect the induction level equalization.

\section{CONCLUSION}

As the population of chronic diseases in China continues to expand, our research results indicate that the government should focus on increasing the level of drug welfare for chronic disease patients in the western rural areas in the future. The policy should be tilted toward the disadvantaged provinces within the region to promote the equalization of the level of drug welfare for patients with chronic diseases in China.

\section{STRENGTHS AND LIMITATIONS OF THIS STUDY}

There was little previous research on the equalization of drug welfare induction level of Chinese patients with chronic diseases.

We set up the index system of drug welfare level by using the questionnaire, and studied it from four aspects of Drug Accessibility Effect Induction level, Drug Price Effect Induction leve, Drug Fairness Effect Induction level, and Drug Health Effect Induction level.

We Creatively used the bivariate Theil-T index method to measure the level of drug welfare induction.

Limitations include the subjectivity of the indicator system and the representativeness of the sample.

\section{DATA AVAILABILITY STATEMENT}

The datasets used or analyzed in the current study are available from the corresponding author upon reasonable request.

\section{REFERENCES}

1. Yach D, Hawkes C, Gould CL, Hofman KJ. The global burden of chronic diseases: Overcoming impediments to prevention and control. JAMA. (2004) 291:2616-22. doi: 10.1001/jama.291.21.2616

2. Beaglehole R, Yach D. Globalisation and the prevention and control of non-communicable disease: the neglected chronic diseases of adults. Lancet. (2003) 362:903-8. doi: 10.1016/S0140-6736(03) 14335-8

3. Hung WW, Ross JS, Boockvar KS, Siu AL. Recent trends in chronic disease, impairment and disability among older adults in the

\section{ETHICS STATEMENT}

Ethical approval (case reference number: KY2017039) was obtained from the Ethics Committee of Nanjing Hospital of Chinese Medicine affiliated with Nanjing University of Chinese Medicine in China, which undertook the study. Informed consent was obtained in written form. All subjects gave their informed consent for inclusion before they participated in the study.

\section{AUTHOR CONTRIBUTIONS}

ST and RZ: designing the manuscript and structure and writing the manuscript. YS: data processing and collected the references. YG: indicator calculation and result analysis. YC: checked the data and edited the language. All authors contributed to the interpretation of the data and approved the final version for submission.

\section{FUNDING}

This study design, data collection, analysis, data interpretation, and writing were supported by the National Natural Science Foundation of China (grant number 71673148), Key Project of Philosophy and Social Science Research in Jiangsu Universities (grant number 2018SJZDI074). The content is solely the responsibility of the authors and does not necessarily represent the official views of these funding organizations. The funding bodies had no role in the design of the study and collection, analysis, and interpretation of data or in writing the manuscript.

\section{ACKNOWLEDGMENTS}

The authors would like to thank all participants included in the study and the medical institutions and medical staff in the four provinces of Gansu, Sichuan, Hebei, and Zhejiang that supported data collection.

\section{SUPPLEMENTARY MATERIAL}

The Supplementary Material for this article can be found online at: https://www.frontiersin.org/articles/10.3389/fpubh. 2020.581533/full\#supplementary-material
United States. BMC Geriatr. (2011) 11:47. doi: 10.1186/1471-231 8-11-47

4. GBD 2016 Causes of Death Collaborators. Global, regional, and national age-sex specific mortality for 264 causes of death, 1980-2016: a systematic analysis for the global burden of disease study 2016. Lancet. (2017) 390:1151210. doi: 10.1016/S0140-6736(17)32152-9

5. Anderson G, Horvath J. The growing burden of chronic disease in America. Public Health Rep. (2004) 119:263-70. doi: 10.1016/j.phr.2004.04.005

6. Hwang W, Weller W, Ireys H, Anderson G. Out-of-pocket medical spending for care of chronic conditions. Health Aff. (2001) 20:26778. doi: 10.1377/hlthaff.20.6.267 
7. Ward BW, Schiller JS, Goodman RA. Multiple chronic conditions among US adults: A 2012 update. Prev Chronic Dis. (2014) 11:E62. doi: $10.5888 /$ pcd11.130389

8. Centers for Disease Control and Prevention. Health, United States (2015).

9. Administration on Aging. A Profile of Older American (2015).

10. Barbour KE, Helmick CG, Boring M, Brady TJ. Vital signs: prevalence of doctor-diagnosed arthritis and arthritis-attributable activity limitation United States, 2013-2015. MMWR Morb Mortal Wkly Rep. (2017) 66:24653. doi: 10.15585/mmwr.mm6609e1

11. National Center for Chronic Disease Prevention and Health Promotion. Healthy Aging: Helping People to Live Long and Productive Lives and Enjoy a Good Quality of Live (2011).

12. United Nations. Global Report by the Secretary-General on the Prevention and Control of Non-communicable Diseases (Report No.A/66/83 (2011).

13. Sun J, Hu CJ, Stuntz M, Hogerzeil H, Liu YL. A review of promoting access to medicines in China - problems and recommendations. BMC Health Serv Res. (2018) 18:125. doi: 10.1186/s12913-018-2875-6

14. Li Q, Chen F, Yang M, Lu LY, Pan J, Li XS, et al. The effect of China's national essential medicine policy on health expenses: evidence from a national study. Inquiry. (2018) 55:1-11. doi: 10.1177/0046958018787057

15. Ji L, Ye Q, Chang JH, Liu GG. A cross-sectional survey on economic burden of type-2 diabetes mellitus patients with oral anti-diabetic drugs therapy in China. Value Health. (2011) 14:A96. doi: 10.1016/j.jval.2011.02.538

16. Lyles A. Pharmacy benefit management companies: do they create value in the US healthcare system? Pharmacoeconomics. (2017) 35:493500. doi: 10.1007/s40273-017-0489-1

17. Bai G, Sen AP, Anderson GF. Pharmacy benefit managers, brand-name drug prices, and patient cost sharing. Ann Intern Med. (2018) 168:4367. doi: 10.7326/M17-2506

18. Grabowski H, Mullins CD. Pharmacy benefit management, cost-effectiveness analysis and drug formulary decisions. Soc Sci Med. (1997) 45:535-44. doi: 10.1016/S0277-9536(96) 00394-2

19. Jenkins TL. Economic effect of an expansion of pharmacy benefits on total health care expenditures by a state medicaid program. J Am Pharm Assoc. (2009) 49:744-50. doi: 10.1331/JAPhA.2009.08112

20. O’Brady S, Gagnon MA, Cassels A. Reforming private drug coverage in Canada: inefficient drug benefit design and the barriers to change in unionized settings. Health Policy. (2015) 119:224-31. doi: 10.1016/j.healthpol.2014.11.013

21. Lohrberg D, Augustin M, Blome C. The definition and role of quality of life in Germany's early assessment of drug benefit: a qualitative approach. Qual Life Res. (2016) 25:447-55. doi: 10.1007/s11136-0151092-6

22. Min L. Study on Evaluation and Promotion Strategy of Drug Welfare Effect of Patients with Chronic Diseases in 10 Provinces Based on Topsis Method. Nanjing: Nanjing University of Chinese Medicine (2018).

23. Yini S. Study on Drug Welfare Effect of Chronic Disease Patients Based on Two-Step Clustering Method. Nanjing: Nanjing University of Chinese Medicine (2018).

24. Li X, Shen JJ, Lu J, Wang Y, Sun M, Li C, et al. Household catastrophic medical expenses in eastern China: determinants and policy implications. BMC Health Serv Res. (2013) 13:506. doi: 10.1186/1472-696313-506

25. Steps in Applying Probability Proportional to Size (PPS) and Calculating Basic Probability Weights. Available online at: http://www.who.int/tb/advisory_ bodies/impact_measurement_taskforce/meetings/prevalence_survey/psws_ probability_prop_size_bierrenbach.pdf (accessed 20, 2020).

26. Yang S. Health Statistics. Beijing: People's Health Press (1992)

27. Xujia C. Study on equalization of basic public cultural services under equal efficiency standards. Contemp Econ Manag. (2016) 38:55-63. doi: 10.13253/j.cnki.ddjjgl.2016.11.010

28. World Health Organization. Measuring Health Workforce Inequalities: Methods and Application to China and India. Human Resources for Health Observer Geneva: WHO Library Cataloguing-in-Publication Data (2010), 5. p.

29. Amarante V, Galván M, Mancero X. Desigualdades en América latina: una medición global. Revis Cepal. (2016) 118:27-47. doi: 10.18356/ee343975-es
30. Sinha A, Rastogi SK. Inequality in access to improved water source: a regional analysis by theil index. Theor Econ Lett. (2015) 5:68390. doi: 10.4236/tel.2015.56079

31. Harper S, Lynch J, Meersman S, Breen N, Davis W, Reichman M. An overview of methods for monitoring social disparities in cancer with an example using trends in lung cancer incidence by area-socioeconomic position and race-ethnicity, 1992-2004. Am J Epidemiol. (2008) 167:88999. doi: 10.1093/aje/kwn016

32. Theil H. Economics and Informtation Theory. Amsterdam: North Holland Publishing Company (1967).

33. Yanqi Z, Guili T, Wenchang W, Ling L, Zengwei Z. Application of gini coefficient and theil index in the study of health resource allocation fairness. Chin J Health Statist. (2008) 34:243-46.

34. Wang Y, Tu Q, Lai Q, Huang L. Fairness or not? Health resources allocation in chongqing-based on theil index. Open J Soc Sci. (2015) 3:11723. doi: $10.4236 /$ jss.2015.37020

35. Liu W, Liu Y, Twum P, Li SX. National equity of health resource allocation in China: data from 2009 to 2013. Int J Equity Health. (2016) 15:68. doi: 10.1186/s12939-016-0357-1

36. Bickenbach F, Mbelu A, Nunnenkamp P. Is foreign aid concentrated increasingly on needy and deserving recipient countries? An analysis of theil indices, 1995-2015. World Dev. (2019) 115:116. doi: 10.1016/j.worlddev.2018.11.003

37. Jiao-xiu W, Hong J. An empirical study on the equalization level of basic education services in China based on the analysis of bivariate theil index. Financ Res. (2013) 6:68-72. doi: 10.19795/j.cnki.cn11-1166/f.2014.01.006

38. Bickenbach F, Liu WH, Nunnenkamp P. How global is FDI? Evidence from the analysis of theil indices. Empirical Econ. (2018) 55:160335. doi: 10.1007/s00181-017-1346-y

39. Guo-Ping H. An empirical study on the equalization level of fiscal expenditure in compulsory education based on the comprehensive analysis of bivariate theil index. Statist Inform Forum. (2012) 27:45-52.

40. Barcelo A. Evaluating the integrated management of chronic diseases. Int J Integr Care. (2019) 19:1568-4156. doi: 10.5334/ijic.s3600

41. Zhou YQ, Yao X, Jian WY. Improving health equity: changes in selfassessed health across income groups in China. Int J Equity Health. (2018) 17:94. doi: 10.1186/s12939-018-0808-y

42. Sun J, Luo HY. Evaluation on equality and efficiency of health resources allocation and health services utilization in China. Int J Equit Health. (2017) 16:127. doi: 10.1186/s12939-017-0614-y

43. Prasad V, De Jesus K, Mailankody S. The high price of anticancer drugs: origins, implications, barriers, solutions. Nat Rev Clin Oncol. (2017) 14:38190. doi: 10.1038/nrclinonc.2017.31

44. Han CL, Hao SC, Han K. "Evaluation of equality and analysis of the regional difference of china's residents health". In: The Sixth International Institute of Statistics \& Management Engineering Symposium. Weihai (2014).

45. Mishuk AU, Fasina I, Qian J. Impact of U.S. federal and state generic drug policies on drug use, spending, and patient outcomes: a systematic review. Res Soc Adm Pharm. (2020) 16:736-45. doi: 10.1016/j.sapharm.2019.08.031

46. Levin J, Ballreich J, Socal MP, Bai G, Anderson G. Consolidated drug purchasing across federal agencies: a solution to improve drug affordability in medicare part D. J Health Care Finanace. (2019) 22:S303. doi: 10.1016/j.jval.2019.04.1467

47. Changyong Y. Practical effects and system concerns of " $4+7$ " drug purchase in quantities. J Southwest Univ National. (2020) 41:34-9.

48. Xinqiao P. The selection of financing system of medical and health service in the rural areas - a view based on the expending behavior in medical and health work for China's peasants. Manag World. (2003) 11:52-63. doi: 10.19744/j.cnki.11-1235/f.2003.11.007

49. Shah A, Shah J, Shah N, Shah R. Smoking prevalence and chronic diseases in China. Lancet Respir Med. (2019) 7:e10. doi: 10.1016/S2213-2600(19)30034-7

50. Eichler H-G, Hurts H, Broich K, Rasi G. Drug regulation and pricing - can regulators influence affordability? N Engl J Med. (2016) 374:18079. doi: 10.1056/NEJMp1601294

51. Waters H. Cheap drugs pulled despite wealth gap in middle-income countries. Nat Med. (2011) 17:1023. doi: 10.1038/nm0911-1023

52. Yang C, Cai W, Li Z, Page AT, Fang Y. The current status and effects of emergency drug shortages in China: perceptions 
of emergency department physicians. PLoS ONE. (2018) 13:e0205238. doi: 10.1371/journal.pone.0205238

53. Tang W, Malone DC. The relationship between medical insurance coverage and medication payments in the us from 1997 to 2015. Value Health. (2018) 21:S90. doi: 10.1016/j.jval.2018. 04.606

54. Hu S. Financing, Pricing and Utilization of Pharmaceuticals in China: The Road to Reform. Washington DC: The World Bank (2010)

55. Monteith S, Glenn T, Bauer R, Conell J, Bauer M. Availability of prescription drugs for bipolar disorder at online pharmacies. $J$ Aff Disord. (2016) 193:59-65. doi: 10.1016/j.jad.2015. 12.043

56. Jiang N, Yin XX, Chen ZY, Li H, Wang J, Zhang J, et al. The sale of antihypertensive drugs by online pharmacies in China: a nationwide cross-sectional survey. Eur J Prev Cardiol. (2020) 1-4. doi: $10.1177 / 2047487319896678$
57. Lamsa E, Timonen J, Mantyselka P, Ahonen R. Pharmacy customers' experiences with the national online service for viewing electronic prescriptions in Finland. Int $J$ Med Inform. (2017) 97:221-8. doi: 10.1016/j.ijmedinf.2016.10.014

Conflict of Interest: The authors declare that the research was conducted in the absence of any commercial or financial relationships that could be construed as a potential conflict of interest.

Copyright $\odot 2020$ Tang, Zhang, Si, Cheng and Gong. This is an open-access article distributed under the terms of the Creative Commons Attribution License (CC BY). The use, distribution or reproduction in other forums is permitted, provided the original author(s) and the copyright owner(s) are credited and that the original publication in this journal is cited, in accordance with accepted academic practice. No use, distribution or reproduction is permitted which does not comply with these terms. 